\title{
Left Atrial Appendage Occlusion: An Alternative to Triple Therapy in Stroke Patients Undergoing Carotid Angioplasty
}

\author{
Ignacio Cruz-González, ${ }^{\mathrm{a}, \mathrm{b}}$ Blanca Trejo-Velasco, ${ }^{\mathrm{a}}$ Laura Redondo-Robles, ${ }^{\mathrm{c}}$ Luis López-Mesonero, ${ }^{\mathrm{c}}$ \\ Rocío González-Ferreiro, ${ }^{\mathrm{a}}$ Jean Carlos Núñez, ${ }^{\mathrm{a}}$ Javier Rodríguez-Collado, ${ }^{\mathrm{a}}$ Pedro L Sánchez ${ }^{\mathrm{a}, \mathrm{b}}$ \\ ${ }^{a}$ Cardiology Department, University Hospital of Salamanca, Biomedical Investigation Institute of Salamanca (IBSAL), Salamanca, Spain \\ ${ }^{b}$ Network Research Centre for Cardiovascular Diseases, Biomedical Research Networking Center on Cardiovascular Diseases (CIBER-CV), Madrid, \\ Spain \\ 'Neurology Department, University Hospital of Salamanca, Salamanca, Spain
}

\section{Dear Sir:}

Significant carotid artery stenosis and atrial fibrillation (AF) concur in up to one quarter of patients suffering an acute ischemic stroke. ' Carotid artery stenting (CAS) is a reasonable treatment alternative in patients with severe carotid artery stenosis at high surgical-risk that presents an acute ischemic stroke. ${ }^{2}$ In this clinical scenario, to decide the best management strategy is challenging, as dual antiplatelet therapy (DAPT) required after CAS, in addition to systemic anticoagulation for the prevention of cardioembolic strokes associated to $A F$, conveys a very high risk of bleeding complications. ${ }^{3}$

We report a single-center case series of four male patients admitted between 1st of October 2019 and 1st of February 2020 for an acute ischemic stroke that presented concurrent severe carotid stenosis and non-valvular atrial fibrillation (NVAF).

Patients were aged 63, 84, 84, and 88 years and displayed high thromboembolic risk as illustrated by increased $\mathrm{CHA}_{2} \mathrm{DS}_{2}-$ VASc score values: 7, 6, 6, and 5, respectively (Table 1). Hemorrhagic hazard was also elevated as depicted by HAS-BLED score: $3,4,3$, and 3 , in relation to baseline comorbidities including history of prior stroke, arterial hypertension, mild to moderate anemia, increased risk of falls and advanced age over 80 years.

All patients had been previously diagnosed with NVAF and were receiving treatment with either optimally dosed acenocumarol $(n=2)$ or direct acting oral anticoagulants $(n=2)$. Two patients presented upper-limb and facial hemiparesis, one patient displayed mild aphasia and one subject exhibited crural paresis. A comprehensive etiologic study conducted during index admission identi-

Table 1. Baseline clinical characteristics

\begin{tabular}{lc}
\hline Characteristic & Value \\
\hline Age $($ yr) & $88,84,63,84$ \\
Male sex & $4(100)$ \\
Hypertension & $2(50)$ \\
Dyslipidemia & $4(100)$ \\
Diabetes mellitus & $1(25)$ \\
Smoker & $2(50)$ \\
Chronic obstructive pulmonary disease & $1(25)$ \\
Previous PCl & $2(50)$ \\
Heart failure & $3(75)$ \\
Left ventricular ejection fraction $(\%)$ & $55,50,35,50$ \\
Peripheral arteriopathy & $1(25)$ \\
$>80 \%$ carotid artery stenosis & $4(100)$ \\
CHA ${ }_{2}$ DS ${ }_{2}$ VASc score & $7,6,6,5$ \\
HAS-BLED score & $3,4,3,3$ \\
Prior ischemic strokes & $1,0,0,2$ \\
Baseline antithrombotic treatment & \\
Acenocumarol & $2(50)$ \\
Direct acting oral anticoagulants & $2(50)$ \\
Aspirin 100 mg daily & $1(25)$ \\
Clopidogrel 75 mg daily & $2(50)$ \\
\hline
\end{tabular}

Values are presented as number (\%).

$\mathrm{PCl}$, percutaneous coronary intervention. 

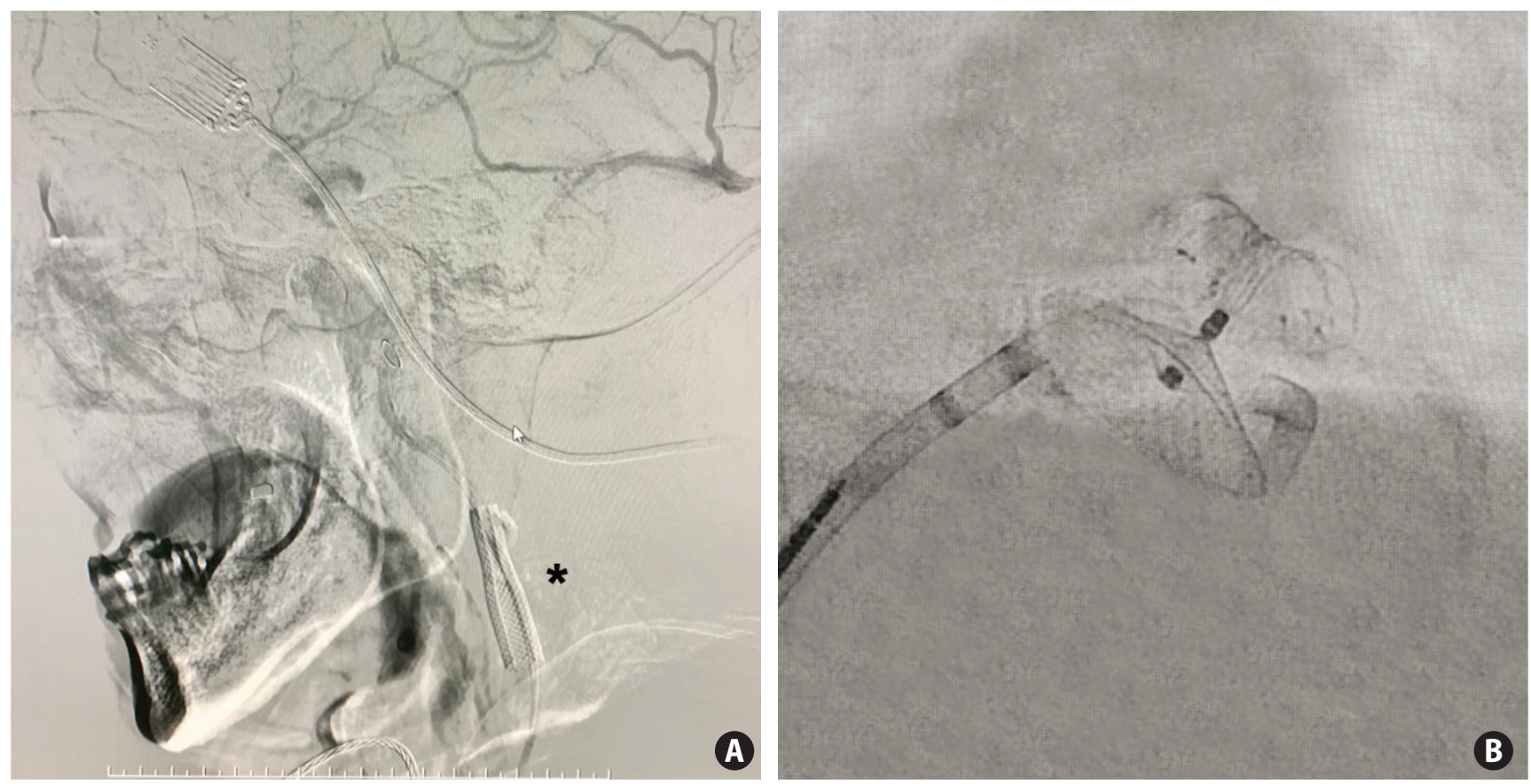

Figure 1. Fluoroscopy images showing (A) left common carotid artery stent (asterisk) and (B) a Lambre (Lifetech Scientific) left atrial occlusion device in a patient that underwent prior percutaneous coronary stenting.

fied $>80 \%$ stenosis of the carotid artery irrigating the ischemic territory in all patients, as an additional mechanism accountable for stroke. Carotid endarterectomy was discarded owing to high surgical risk and it was decided to perform CAS and subsequent left atrial appendage occlusion (LAAO) in a separate procedure to avoid triple antithrombotic therapy. Ethics approval was obtained from the Institutional Review Board and the patients gave written informed consent.

First, percutaneous stenting of the symptomatic carotid artery was performed and the patients were initiated on DAPT. LAAO was subsequently performed either with Amulet (Abbott Vascular, Chicago, IL, USA) 18 and $20 \mathrm{~mm}$ or Lambre (Lifetech Scientific, Shenzhen, China) 26/32 and 34/20 mm devices, under light sedation with transesophageal echocardiography guidance (Figure 1). All procedures were successful and there were no peri-procedural complications. All patients were discharged home on DAPT and, at a median follow-up period of 45 days, no complications, thromboembolic or bleeding events occurred and control transesophageal echocardiography ruled out peri-device leaks or thrombus.

LAAO is an effective alternative to systemic anticoagulation for the prevention of thromboembolic events in patients with NVAF at highest-risk of bleeding complications. ${ }^{4}$ LAAO may also be recommended after coronary artery stenting, to avoid triple antithrombotic therapy. ${ }^{5}$ However, to the best of our knowledge, ours is the first case-series to report LAAO in high bleeding risk NVAF patients undergoing recent CAS after an acute ischemic stroke, to enable safe withdrawal of systemic anticoagulation while maintaining adequate protection against subsequent thromboembolic events.

In our sample, LAAO after CAS was safe and no patients presented ischemic or bleeding complications during initial follow-up.

The rationale behind treating carotid stenosis in the first place is the same behind treating carotid before coronary stenosis when concomitant: ${ }^{6}$ a decrease in cardiac output may worsen ischemia downstream a carotid stenosis. Although carotid endarterectomy is considered in general safer and more effective than $\mathrm{CAS}^{7}$, this is doubtful when concomitant NAVF is present, as NAVF has been an exclusion criteria in trials addressing safety and efficacy of carotid endarterectomy. ${ }^{8}$ In these patients, CAS was preferred because it does not oblige to stop anticoagulation ${ }^{9}$ and it is used in combination with a device that can stop cardiac emboli generated by reflex alteration of the cardiac rhythm by carotid baroreceptors. As stroke patients often suffer from both NVAF and carotid stenosis, the safer and more effective combination of treatments merits further study.

\section{References}

1. Chang YJ, Ryu SJ, Lin SK. Carotid artery stenosis in ischemic stroke patients with nonvalvular atrial fibrillation. Cerebrovasc Dis 2002;13:16-20. 
2. Bonati LH, Dobson J, Featherstone RL, Ederle J, van der Worp $H B$, de Borst GJ, et al. Long-term outcomes after stenting versus endarterectomy for treatment of symptomatic carotid stenosis: the International Carotid Stenting Study (ICSS) randomised trial. Lancet 2015;385:529-538.

3. Capodanno D, Angiolillo DJ. Management of antiplatelet and anticoagulant therapy in patients with atrial fibrillation in the setting of acute coronary syndromes or percutaneous coronary interventions. Circ Cardiovasc Interv 2014;7:113-124.

4. Boersma LV, Ince H, Kische S, Pokushalov E, Schmitz T, Schmidt $B$, et al. Efficacy and safety of left atrial appendage closure with WATCHMAN in patients with or without contraindication to oral anticoagulation: 1-year follow-up outcome data of the EWOLUTION trial. Heart Rhythm 2017;14:1302-1308.

5. Pison L, Potpara TS, Chen J, Larsen TB, Bongiorni MG, Blom-

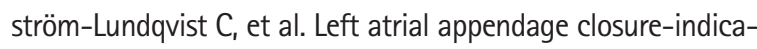
tions, techniques, and outcomes: results of the European Heart Rhythm Association Survey. Europace 2015;17:642-646.

6. Paraskevas KI, Nduwayo S, Saratzis AN, Naylor AR. Carotid stenting prior to coronary bypass surgery: an updated systematic review and meta-analysis. Eur J Vasc Endovasc Surg 2017; 53:309-319.
7. Müller MD, Lyrer P, Brown MM, Bonati LH. Carotid artery stenting versus endarterectomy for treatment of carotid artery stenosis. Cochrane Database Syst Rev 2020;2:CD000515.

8. Rosenfield K, Matsumura JS, Chaturvedi S, Riles T, Ansel GM, Metzger DC, et al. Randomized trial of stent versus surgery for asymptomatic carotid stenosis. N Engl J Med 2016;374:10111020.

9. Brand $A R$, de Borst GJ. Evidence for periprocedural antiplatelet therapy, heparinization and bridging of coumarin therapy in carotid revascularization. J Cardiovasc Surg (Torino) 2017;58:143151.

Correspondence: Blanca Trejo-Velasco

Cardiology Department, University Hospital of Salamanca, Biomedical Investigation Institute of Salamanca (IBSAL), Paseo San Vicente 182, 37007, Salamanca, Spain

Tel: +34-626412210

Fax: +34-923291299

E-mail: treejooblanca@hotmail.com

Received: March 28, 2020

Revised: May 16, 2020

Accepted: May 18, 2020

Ignacio Cruz-González is proctor for Lifetech and Abbott Vascular. No other relationship with industry exists. 